\title{
History and Background of Quality Measurement
}

\author{
Jonathan Chun, MD ${ }^{1}$ Andrea Chao Bafford, MD, FACS ${ }^{1}$ \\ 1 Section of Colon and Rectal Surgery, Division of General and \\ Oncologic Surgery, Department of Surgery, University of Maryland \\ School of Medicine, University of Maryland Medical Center, \\ Baltimore, Maryland \\ Address for correspondence Andrea Chao Bafford, MD, FACS, Section of \\ Colon and Rectal Surgery, Division of General and Oncologic Surgery, \\ Department of Surgery, University of Maryland School of Medicine, \\ University of Maryland Medical Center, 22. S Greene Street, S3AX04, \\ Baltimore, MD 21201 (e-mail: abafford@smail.umaryland.edu).
}

Clin Colon Rectal Surg 2014;27:5-9.
Abstract Keywords
- surgical quality
- quality improvement
- quality measures
- history
Health care quality measurement has become increasingly emphasized, as providers and administrators respond to public and government demands for improved patient care. This article will review the evolution of surgical quality measurement and improvement from its infancy in the 1850 s to the vast efforts being undertaken today.

CME Objectives: On completion of this article, the reader should be able to summarize the background of surgical quality measurement and improvement and be familiar with initiatives being performed today.

\section{The Evolution of Health Care Quality Measurement and Improvement}

In recent years, health care quality measurement has become increasingly emphasized, as providers and hospital administrators respond to public and government demands to minimize errors and improve patient care. The concept of evidence-based quality improvement was present as early as the 1850s when Florence Nightingale demonstrated that basic sanitation and hygiene standards led to decreased mortality when caring for soldiers wounded in the Crimean War. ${ }^{1}$

Ernest Amory Codman, a surgeon from Harvard Medical School and the Massachusetts General Hospital, is often considered the founder of outcomes studies and evidencebased medicine. He kept track of his patients via "End Result Cards"-index cards that contained patient demographics, diagnoses, treatments, and outcomes. ${ }^{2}$ He believed that understanding why treatments were unsuccessful was the foundation for improving the care of future patients. In 1913, he and gynecologist Edward Martin cofounded the American College of Surgeons (ACS). Together, they formed several committees of the ACS, including "the Committee for Hospital Standardization," of which Dr. Codman was chair. Dr.
Codman wrote, "We believe it is the duty of every hospital to establish a follow-up system, so that as far as possible, the result of every case will be available at all times for investigation by members of the staff, the trustees, or administration, or by other authorized investigators or statisticians."3 In 1917, the ACS adopted his "End Result System" for its Hospitalization Standardization Program. This program would establish "minimum standards" for hospitals, ${ }^{4}$ including the following:

- Organizing hospital medical staffs;

- Limiting staff membership to well-educated, competent, and licensed physicians and surgeons;

- Framing rules and regulations to ensure regular staff meetings and clinical reviews;

- Keeping medical records that included the history, laboratory, physical examination; and

- Establishing supervised diagnostic and treatment facilities such as clinical laboratory and radiology departments.

By 1952, the American College of Physicians, the American Hospital Association, the American Medical Association, and the Canadian Medical Association would join forces with the ACS to form the Joint Commission on Accreditation of Healthcare Organizations (JCAHO). ${ }^{3-5}$

The original Social Security Act, passed in1935 under Franklin D. Roosevelt's presidency, failed to address medical benefits. It was not until 1965, when amendments XVIII and XIX created Medicare and Medicaid, respectively, that United States health care began to fall under federal supervision. Under Title XVIII, Congress enacted a set of rules called
Issue Theme Quality Measurement and Improvement in Colon and Rectal Surgery; Guest Editor, Jeffery M. Nelson, MD
Copyright (c) 2014 by Thieme Medical Publishers, Inc., 333 Seventh Avenue, New York, NY 10001, USA.

Tel: +1(212) 584-4662.
DOI http://dx.doi.org/ 10.1055/s-0034-1366912. ISSN 1531-0043. 
"Conditions of Participation." These rules set hospital mandates, such as medical staff credentials and 24-hour nursing services. ${ }^{6}$

In the late 1980 s, JCAHO implemented a rigorous set of accreditation standards, which reflected concepts presented by Avedis Donabedian in his 1966 article entitled "Evaluating the Quality of Medical Care."” According to Donabedian, three facets of quality measurement exist: structure, or the characteristics of health care delivery systems; process, or what and how care is provided; and outcomes, or the consequences of care. In 1998, the Institute of Medicine (IOM) initiated the Quality of Health Care in America project, a commission tasked with achieving a threshold improvement in health care quality over a 10year period. The committee's initial focus was on quality concerns that fall into the category of medical errors. The result was the pivotal report, "To Err is Human: Building a Safer Health System." ${ }^{8}$ This article emphasized the existing safety gaps in U.S. health care, noting that as many as 98,000 people die in U.S. hospitals each year due to medical errors. The IOM's “Crossing the Quality Chasm: A New Health System for the 21st Century,"9 published in 2001, further described the failure of our health care delivery system to provide "consistent, high-quality medical care to all people." A "fundamental, sweeping redesign of the entire health system" was called for. These two IOM reports triggered demands by the nation's people to improve the quality of U.S. health care and efforts by health care organizations and providers to improve their practices.

Donabedian's structure-process-outcome model continues to be used in surgical quality research today. Structural measures include a broad catalog of variables reflecting the setting or system in which care is delivered. Examples of measurable structural attributes relevant to surgical care include operative volumes; specialty qualifications, such as "Bariatric Surgery Center of Excellence," "National Comprehensive Cancer Network Cancer Center," and "Level 1 Trauma Center"; subspecialty training by the operating surgeons; and the presence of advanced technologies, such as hybrid operating rooms or robotic surgery. Of these variables, operative volume, measured at either the surgeon or hospital level, is the most frequently used surrogate for surgical quality. Numerous studies have evaluated the relationship between surgical volumes and outcomes. Using data collected through the Veterans Health Administration National Surgical Quality Improvement Program, Khuri et $\mathrm{al}^{10}$ examined the relationship between surgical volume and outcome in eight commonly performed operations: nonruptured abdominal aortic aneurysmectomy, vascular infrainguinal reconstruction, carotid endarterectomy, lung lobectomy/pneumonectomy, open and laparoscopic cholecystectomy, partial colectomy, and total hip arthroplasty. In all, 68,631 operations were analyzed. No statistically significant associations between procedure or specialty volume and 30-day mortality rate were found. On the contrary, Birkmeyer et al demonstrated that surgeon volume was inversely related to operative mortality in 474,108 patients who underwent one of the eight procedures for cardiovascular disease or cancer. ${ }^{11}$ With- in colorectal surgery, studies have demonstrated lower local recurrence rates and improved disease-specific survival in rectal cancer patients treated by higher volume colorectal surgery-trained surgeons compared with noncolorectaltrained surgeons. ${ }^{12}$ A systematic review looking at the effect of both hospital and physician volumes on outcomes showed that high volume is associated with better outcomes across a wide variety of procedures and conditions, but that the magnitude of these associations varied widely. ${ }^{13}$ Studying structural variables is attractive because they are, in general, easily and inexpensively measured. Changing these variables, however, is often challenging.

The establishment and adoption of evidence-based practice guidelines presumably improves surgical outcomes. Measuring adherence to effective processes is therefore a means of assessing health care quality. Process measures are frequently used in this capacity in nonsurgical specialties. An example is compliance of primary care physicians with preventive care guidelines, such as breast and colon cancer screening. Within surgery, the Surgical Care Improvement Project (SCIP) program, sponsored by the Centers for Medicare and Medicaid Services (CMS), involves the review of measures that ensure quality care is given. This important initiative will be discussed in detail later. Unlike structural measures, process measures are more readily amended or performed to improve health care quality. A recent study, however, revealed only a weak association between compliance with process measures and risk-adjusted outcomes. ${ }^{14}$

Quality of surgical care is perhaps best assessed by outcome measures, as every intervention is associated with an expected result. Studies have indeed demonstrated that measuring outcomes leads to improved outcomes. ${ }^{15}$ Common outcome measures include operative morbidity and mortality, length of hospital stay, readmission rates, and more recently patient satisfaction and quality of life scores. Because of significant variation between patients with respect to their disease states and comorbidities, which in turn affect their operative risk, validated risk adjustment models are necessary to accurately compare outcomes. ${ }^{16}$ The first risk-adjustment models were developed for cardiac surgery. ${ }^{17}$ It was not until the National VA Surgical Risk Study (NVASRS) was completed that the first validated tool for measuring and comparing quality of noncardiac surgery came into existence. ${ }^{18}$ From the NVASRS spawned the VA National Surgical Quality Improvement Program (NSQIP) and subsequent large-scale initiatives aimed at measuring and improving surgical outcomes.

One of the most recent initiatives is the National Strategy for Quality Improvement in Health Care, also known as the National Quality Strategy. The 2010 Affordable Care Act required the Secretary of Health and Human Services to establish this strategy as a way to address the seeming disconnect between health care costs and outcomes in the United States. In spite of $\$ 2.5$ trillion dollars in annual health care costs, the highest cost per capita in the world, life expectancy is lower and infant mortality is higher in the United States than in other developed countries. The objectives and priorities of the National Quality Strategy, as 
detailed in the 2012 annual progress report to Congress, ${ }^{19}$ are as follows.

\section{National Quality Strategy's Three Aims}

1. Better Care: Improve the overall quality of care, by making health care more patient centered, reliable, accessible, and safe.

2. Healthy People/Healthy Communities: Improve the health of the U.S. population by supporting proven interventions to address behavioral, social, and environmental determinants of health in addition to delivering higher-quality care.

3. Affordable Care: Reduce the cost of quality health care for individuals, families, employers, and government.

\section{National Quality Strategy's Six Priorities}

1. Making care safer by reducing harm caused in the delivery of care.

2. Ensuring that each person and family is engaged as partners in their care.

3. Promoting effective communication and coordination of care.

4. Promoting the most effective prevention and treatment practices for the leading causes of mortality, starting with cardiovascular disease.

5. Working with communities to promote wide use of best practices to enable healthy living.

6. Making quality care more affordable for individuals, families, employers, and governments by developing and spreading new health care delivery models.

The results of this initiative will certainly bear watching in the years to come.

\section{Background of Specific Quality Measurement Programs}

\section{National Surgical Quality Improvement Project}

Prompted by a 1986 congressional mandate, the Veterans Health Administration conducted the NVASRS between October 1, 1991, and December 31, 1993. The aim of this study was to develop risk-adjustment models for predicting surgical outcomes and comparing quality of surgical care among multiple centers. Preoperative, operative, and 30-day outcome data were prospectively collected at 44 Veteran's Affairs Medical Centers (VAMC). Risk-adjustment models for 30-day mortality and morbidity rates were developed for each of the following subspecialties: general surgery, vascular surgery, orthopedic surgery, urology, cardiac surgery, thoracic surgery, neurosurgery, plastic surgery, and otolaryngology. ${ }^{18}$ Based on these results, NSQIP was established in January 1994, and has since become the principal means of assessing the quality of surgical care for veterans. ${ }^{20}$ Data on 95,000 to 100,000 major surgical procedures are collected from 123 VAMCs annually.

In the VA NSQIP's first 10 years, 30-day postoperative mortality decreased by $27 \%$. An even more dramatic decline was seen in postoperative morbidity. The number of patients undergoing major surgery in the NSQIP who experienced 1 or more of 20 predefined postoperative complications decreased from 17.8 to $9.8 \%$ over 10 years. Over the same time period, the median length of hospital stay declined by 5 days. ${ }^{21}$ From the NSQIP's inception in 1991 to 2006, 30-day postoperative mortality declined by $47 \%$ and morbidity by $43 \%$ at VA hospitals. ${ }^{22}$ Encouraged by the VA NSQIP's success, private sector hospitals became interested in participating in a validated, risk-adjusted, outcomes-based program to measure and improve the quality of surgical care. In 1999, three university-affiliated surgeons and their hospitals (Darrell Campbell Jr., University of Michigan; Aaron Fink, Emory University; and Robert Mentzer Jr., University of Kentucky at Lexington) participated in an initial cohort testing of the NSQIP in the private sector. Using processes and definitions used by the VA NSQIP, data were collected on all major general and vascular operations performed at these institutions. Analysis of the results after the first year of data collection showed that the predictive and risk-adjustment models were equally applicable to the VA and non-VA populations. ${ }^{18}$ Following this pilot study, the ACS with support from the Agency for Healthcare Research and Quality (AHRQ) developed NSQIP for private hospitals. In 2004, the ACS NSQIP was initiated at the national level, the first of its kind.

The ACS NSQIP provides a prospective, peer-controlled, validated database of preoperative to 30-day postoperative surgical outcomes based on clinical data. Since the program was launched, participating hospitals have seen significant improvements in quality and cost savings through use of the program's tools, reports, and analysis. Hall et $\mathrm{al}^{15}$ showed that $82 \%$ of hospitals participating in ACS NSQIP improved morbidity rates and 66\% improved mortality. Further, each hospital prevented 250 to 500 complications, saved 12 to 36 lives, and reduced costs by millions of dollars, annually. Hospitals of all types-large and small, urban and rural, and teaching and nonteaching-improved their quality of care. ${ }^{15}$ Additional studies have demonstrated similar improvements in operative morbidity and cost effectiveness. $^{23,24}$ Today, there are nearly 500 hospitals that participate in ACS NSQIP.

\section{Surgical Care Improvement Project}

The Surgical Infection Prevention (SIP) project was implemented in 2002 in a concerted effort to reduce the number of postoperative surgical infections. This was a collaboration between CMS and the Centers for Disease Control and Prevention. SIP measure data began to be collected by hospitals in July 2004. In 2006, the SIP measures transitioned to the SCIP. These measures were targeted as strategies to improve surgical quality and outcomes. The SCIP measures now consist of the following:

1. Appropriate timing of prophylactic antibiotics (within 1 hour of incision);

2. Appropriate selection of antibiotics;

3. Discontinuation of antibiotics within 24 hours of the end of surgery; 
4. Appropriate blood glucose control in cardiac surgery;

5. Appropriate hair removal method;

6. Urinary catheter removal by postoperative day 2 ;

7. Perioperative temperature management;

8. Continuation of preoperative $\beta$-blockers;

9. Appropriate venous thromboembolism (VTE) prophylaxis; and

10. Appropriate timing of VTE prophylaxis.

Data collection on SCIP measures has become the focus of many hospitals' quality improvement efforts. While it seems logical to conclude that improved adherence to these widely accepted measures would result in improved outcomes, rigorous follow-up studies are necessary to demonstrate this. A study by Pastor et al in 2010 examined the relationship between compliance with SCIP measures and surgical site infections (SSIs) in colorectal patients. ${ }^{25}$ Unfortunately, their data did not demonstrate a significant reduction in the rate of SSI in spite of significantly improved compliance with SCIP measures. While more studies are needed to examine the validity of the SCIP measures, the results of the Pastor study raise legitimate questions about committing significant resources to improving compliance with SCIP measures for an uncertain benefit.

\section{Surgical Clinical Outcomes Assessment Program}

The Surgical Clinical Outcomes Assessment Program (SCOAP) was modeled after the Cardiac Clinical Outcomes Assessment Program (COAP). ${ }^{26}$ Instituted in 1997, COAP is a quality improvement project in the state of Washington involving all hospitals performing percutaneous coronary interventions (PCIs) and coronary artery bypass graft (CABG) surgery. Prospective process and outcome data are being collected on every patient undergoing $\mathrm{PCI}$ or CABG procedures in the state. Regular reports are given to hospitals, which, while protecting the identity of the hospitals, allow them to compare themselves to other hospitals. Data are protected from third-party disclosure by Washington State statutes.

Some of the key tenets of COAP, which were retained for SCOAP, are voluntary involvement; physician leadership; protection of sensitive performance data to promote candid appraisal and discussion; an emphasis on high-quality, accurate data regarding process and outcome measures; and recognition of variability in patient risk factors at disparate institutions. The initial targeted procedures for SCOAP were colorectal resections, bariatric procedures, and appendectomies. This has since expanded to include vascular surgery, pediatric surgery, and neurosurgery.

While NSQIP looks exclusively at outcomes and SCIP looks exclusively at processes, SCOAP attempts to combine these two components to standardize best practices and ensure the best outcomes. In a review from 2012, the SCOAP collaborative noted several concrete changes among the institutions participating in SCOAP. For example, with improved preoperative imaging, the rate of negative appendectomy decreased. By improving glycemic control in diabetic patients undergoing colorectal resection, as well as increasing leak testing, adverse events significantly decreased. In addition, a cost saving of more than $\$ 60$ million dollars in 2009 was seen after participation in SCOAP. ${ }^{27}$ The presence of a SCOAP checklist for the relevant procedures is an effort to decrease variability in the relevant process measures.

\section{Summary}

Health care quality measurement and improvement has evolved from the early works of Florence Nightingale; Ernest Codman, who is frequently considered the founder of evidence-based medicine; and Avedis Donabedian, who introduced the structure-process-outcome paradigm. Largely motivated by increasing public awareness of health care shortcomings and demand for change, the turn of the 21st century brought with it numerous initiatives aimed at improving health care quality, frequently in the form of largescale registries. As we learn from the data collection process and results, new levels of health care safety, efficiency, and quality should be achieved.

\section{References}

1 Kudzma EC. Florence Nightingale and healthcare reform. Nurs Sci Q 2006;19(1):61-64

2 Donabedian A. The end results of health care: Ernest Codman's contribution to quality assessment and beyond. Milbank Q 1989; 67(2):233-256, discussion 257-267

3 Mallon B. Ernest Amory Codman: The End Result of a Life in Medicine. Philadelphia, PA: W. B. Saunders; 1999

4 Roberts JS, Coale JG, Redman RR. A history of the Joint Commission on Accreditation of Hospitals. JAMA 1987;258(7):936-940

5 Neuhauser D. Ernest Amory Codman, M.D., and end results of medical care. Int J Technol Assess Health Care 1990;6(2): 307-325

6 Institute of Medicine. Medicare: A Strategy for Quality Assurance, Vols. I and II. Washington, DC: National Academy Press; 1990

7 Donabedian A. Evaluating the quality of medical care. 1966. Milbank Q 2005;83(4):691-729

8 Institute of Medicine. To Err Is Human: Building a Safer Health System. Washington, DC: National Academy Press; 1999

9 Institute of Medicine. Crossing the Quality Chasm: A New Health System for the 21st Century. Washington, DC: National Academy Press; 2001

10 Khuri SF, Daley J, Henderson W, et al. Relation of surgical volume to outcome in eight common operations: results from the VA National Surgical Quality Improvement Program. Ann Surg 1999; 230(3):414-429, discussion 429-432

11 Birkmeyer JD, Stukel TA, Siewers AE, Goodney PP, Wennberg DE, Lucas FL. Surgeon volume and operative mortality in the United States. N Engl J Med 2003;349(22):2117-2127

12 Porter GA, Soskolne CL, Yakimets WW, Newman SC. Surgeonrelated factors and outcome in rectal cancer. Ann Surg 1998; 227(2):157-167

13 Halm EA, Lee C, Chassin MR. Is volume related to outcome in health care? A systematic review and methodologic critique of the literature. Ann Intern Med 2002;137(6):511-520

14 Ingraham AM, Cohen ME, Bilimoria KY, et al. Association of surgical care improvement project infection-related process measure compliance with risk-adjusted outcomes: implications for quality measurement. J Am Coll Surg 2010;211(6): 705-714 
15 Hall BL, Hamilton BH, Richards K, Bilimoria KY, Cohen ME, Ko CY. Does surgical quality improve in the American College of Surgeons National Surgical Quality Improvement Program: an evaluation of all participating hospitals. Ann Surg 2009;250(3):363-376

16 Iezzoni LI. Using risk-adjusted outcomes to assess clinical practice: an overview of issues pertaining to risk adjustment. Ann Thorac Surg 1994;58(6):1822-1826

17 Daley J. Criteria by which to evaluate risk-adjusted outcomes programs in cardiac surgery. Ann Thorac Surg 1994;58(6):1827-1835

18 Khuri SF, Daley J, Henderson W, et al. The National Veterans Administration Surgical Risk Study: risk adjustment for the comparative assessment of the quality of surgical care. J Am Coll Surg 1995;180(5):519-531

19 United States Department of Health and Human Services. 2012 Annual Progress Report to Congress. National Strategy for Quality Improvement in Health Care. 2012. Available from the Agency for Healthcare Research and Quality Web site: http://www.ahrq.gov/ workingforquality/nqs/nqs2012annlrpt.pdf; Accessed May 31, 2013

20 Khuri SF, Daley J, Henderson W, et al; National VA Surgical Quality Improvement Program. The Department of Veterans Affairs' NSQIP: the first national, validated, outcome-based, risk-adjusted, and peer-controlled program for the measurement and enhancement of the quality of surgical care. Ann Surg 1998;228(4):491-507

21 Khuri SF, Daley J, Henderson WG. The comparative assessment and improvement of quality of surgical care in the Department of Veterans Affairs. Arch Surg 2002;137(1):20-27
22 Khuri SF, Henderson WG, Daley J, et al; Principal Site Investigators of the Patient Safety in Surgery Study. The patient safety in surgery study: background, study design, and patient populations. J Am Coll Surg 2007;204(6):1089-1102

23 Guillamondegui OD, Gunter OL, Hines L, et al. Using the National Surgical Quality Improvement Program and the Tennessee Surgical Quality Collaborative to improve surgical outcomes. J Am Coll Surg 2012;214(4):709-714, discussion 714-716

24 Steinberg SM, Popa MR, Michalek JA, Bethel MJ, Ellison EC. Comparison of risk adjustment methodologies in surgical quality improvement. Surgery 2008;144(4):662-667, discussion 662-667

25 Pastor C, Artinyan A, Varma MG, Kim E, Gibbs L, Garcia-Aguilar J. An increase in compliance with the Surgical Care Improvement Project measures does not prevent surgical site infection in colorectal surgery. Dis Colon Rectum 2010;53(1):24-30

26 Flum DR, Fisher N, Thompson J, Marcus-Smith M, Florence M, Pellegrini CA. Washington State's approach to variability in surgical processes/outcomes: Surgical Clinical Outcomes Assessment Program (SCOAP). Surgery 2005;138(5):821-828

27 Kwon S, Florence M, Grigas P, et al; SCOAP Collaborative, Writing Group for the SCOAP Collaborative. Creating a learning healthcare system in surgery: Washington State's Surgical Care and Outcomes Assessment Program (SCOAP) at 5 years. Surgery 2012;151(2): 146-152 